\title{
EMPLEO Y CARRERAS LABORALES EN CORREOS DE ESPAÑA, 1890-1935*
}

JORDI DOMENECH

Universidad Carlos III de Madrid ${ }^{\mathrm{a}}$

\begin{abstract}
The development of postal services has played an indisputable role in industrialization, market integration and state formation. Smooth functioning of these services depended on the existence of a well-paid and motivated body of civil servants. I study the organization of the internal labour market for civil servants in postal services in Spain from 1890 to 1935 showing a career in the postal services offered high entry wages, growing wages over the life cycle, and a secure job until retirement. There were two downsides to pursuing a career in the postal services. Firstly, entry and promotion depended on the expansion of employment. Secondly, nominal wages were upward rigid, causing large real wage losses during WWI.
\end{abstract}

Keywords: postal services, internal labour markets, wages, bureaucracy, Spain, life-cycle earnings, mandatory retirement, efficiency wages

JEL Codes: J45, L32, L87, M12, N34

* Received 22 September 2014. Accepted 17 February 2015. El autor agradece la ayuda de Correos y Telégrafos de España, S. A. en el marco del proyecto «Una historia económica de Correos y Telégrafos de España», liderado por Juan Carmona y Joan Ramon Rosés. El autor agradece muy especialmente la ayuda y disposición del personal del archivo y biblioteca de Correos y Telégrafos.

a Departamento de Ciencias Sociales, Calle Madrid, 126, 28903 Getafe (Madrid), Spain, Email: jdomenec@clio.uc3m.es. Telephone number: (+34) 916249809. 


\section{RESUMEN}

Correos tuvo un papel indiscutible en la industrialización, la integración de mercados y la consolidación del Estado. Su funcionamiento exigía la existencia de un cuerpo de funcionarios motivados, por lo que estudiamos el mercado interno de trabajo de Correos de España entre 1890 y 1935. Se presenta la evolución del empleo en relación con el tráfico postal y la evolución de los salarios. La carrera funcionarial ofrecía salarios de entrada altos, promociones automáticas y trabajo seguro hasta la jubilación. Sin embargo, la entrada y la promoción dependían crucialmente de la expansión del empleo. Además, los salarios nominales eran rígidos al alza, lo que provocó el deterioro de los salarios reales entre 1913 y 1920.

Palabras clave: Correos, Telégrafos, mercados internos de trabajo, salarios, burocracia, España, salarios durante el ciclo vital, jubilación obligatoria, salarios de eficiencia

\section{INTRODUCCIÓN}

El desarrollo económico precisa de la puesta en funcionamiento de un sistema eficaz de comunicaciones a distancia —postal, telegráfico o telefónico- que complemente las infraestructuras de transportes en la consolidación e integración de los mercados domésticos e internacionales de bienes y servicios, y en la profundización y expansión del papel del Estado en la economía. La eficacia de tecnologías de la comunicación como el telégrafo o el servicio de correos dependía a su vez de la existencia de un cuerpo de funcionarios bien motivados y pagados que no entorpeciera la fluidez de las comunicaciones. En este sentido, las dificultades en la gestión de recursos humanos en los servicios de correos o telégrafos se asemejaban bastante a los de una gran empresa moderna: la necesidad de disciplinar e incentivar la honradez y el esfuerzo de grupos grandes de trabajadores sin que sea necesario incurrir en costes excesivos de supervisión.

Ya desde mitad del siglo XIX, en las empresas industriales se empezaron a gestionar sus recursos humanos para asegurar la fluidez de la producción, el aumento de la productividad, la progresión del capital humano específico de la empresa y el cuidado de capital, especialmente maquinaria delicada y valiosa. Esta situación favoreció la aparición de mercados internos de trabajo y de crecientes rigideces en el ajuste del salario nominal en sectores caracterizados por la existencia de grandes empresas como el textil o el automovilístico (Huberman, 1995; Raff y Summers, 1987; Raff, 1988; Camps, 1985 y 1995; Domenech, 2008; Brown y Neumeier, 2001). Estos mercados internos se caracterizaban por promociones en la jerarquía de la empresa 
basadas en la antigüedad, la existencia de escalas rígidas de salarios y el disfrute de un salario cada vez mayor a medida que el trabajador acumulaba años de experiencia en la empresa. Típicamente, al estar el salario asociado a la antigüedad y no a la productividad, los trabajadores que acumulaban más años de experiencia en la empresa mantenían salarios elevados, a pesar del más que posible deterioro de su productividad individual a medida que el trabajador o la trabajadora se aproximaban a la vejez.

Problemas parecidos de supervisión y vigilancia de la fuerza de trabajo aparecieron en el sector servicios, donde el empleador tenía dificultades para conseguir información sobre el rendimiento y la honestidad de sus trabajadores. Esto era particularmente importante en la banca, cuyo funcionamiento exigía empleados cuya pulcritud y honestidad estuviera fuera de toda duda. Para la banca, dadas las tecnologías del momento, era especialmente difícil vigilar a sus empleados en oficinas distantes. Este problema era cada vez más serio a medida que la red de oficinas bancarias se extendía. La aparición de mercados internos de trabajo se ha documentado para el caso de la banca durante el siglo XIX en el Reino Unido y Australia (Boot, 1991; Seltzer, 2010; Seltzer y Simons, 2001; Seltzer, 2004).

Los mercados internos de trabajo también aparecieron en otras empresas de servicios en las que era difícil medir la productividad individual. Los mercados internos surgieron rápidamente en las grandes empresas de ferrocarriles del siglo XIX (Howlett, 2004). Dada la creciente complejidad administrativa de las grandes empresas y del propio Estado, se produjo una creciente demanda de oficinistas que también se someterían a los mecanismos de promoción por antigüedad y percibirían emolumentos crecientes con la experiencia y la edad a partir de rígidas escalas salariales y de sistemas de promoción internos basados en la antigüedad (Boot, 1999).

Los estudios mencionados refieren a empresas o sectores ubicados en países ya desarrollados a finales del siglo XIX, como el Reino Unido, Alemania o Estados Unidos. En cambio, se ha estudiado relativamente poco la aparición y el funcionamiento de mercados internos de trabajo en países más periféricos y menos desarrollados, como España, Italia o Japón. La gestión de personal en empresas textiles del área de Barcelona la han estudiado con detalle Camps $(1985,1990)$ y Domenech (2008); también son bastante conocidas las experiencias de las grandes empresas siderúrgicas vizcaínas (Fernández de Pinedo, 1992; Escudero, 2001). Existen estudios detallados sobre la gestión de personal en empresas de ferrocarril españolas en la primera mitad del siglo XX, especialmente en el caso de la compañía de Madrid a Zaragoza y Alicante (MZA) (Ballesteros y Martínez Vara, 2001 y 2001b; Martínez Vara, 2006). Existe también un estudio muy detallado del personal del Banco de España en los siglos XVIII y XIX (Moreno, 2001) y un excelente estudio sobre el empleo femenino en Telefónica desde 1924 hasta 1980 (Borderías, 1993). Para Japón, por otra parte, también existen varios estudios publicados en inglés sobre el funcionamiento de los mercados de 
trabajo en grandes empresas privadas textiles y de titularidad pública en el caso de Correos, aunque no estrictamente sobre el tema de mercados internos y, más generalmente, sobre la demanda de trabajo de mujeres jóvenes (Saxonhouse y Wright, 1984; Hunter, 2009).

La literatura económica sobre los fundamentos teóricos de los mercados «internos» de trabajo es extensa, pero como característica general incide en la existencia de información asimétrica entre el trabajador y su empleador en contextos en los que el empleador necesita asegurarse la cooperación de los trabajadores. Esta información asimétrica se refiere tanto a la calidad intrínseca del trabajador, como al esfuerzo y la honradez en su actividad laboral. Los modelos de mercados internos y la rigidez salarial se agrupan en varias familias, pero todos coinciden en la dificultad de medir el rendimiento individual y en el desempleo como mecanismo que disciplina al trabajador (Schapiro y Stiglitz, 1984). Una primera familia de modelos establece la posibilidad de equilibrios cooperativos entre empleadores y trabajadores, en los cuales los trabajadores revelan su productividad potencial a cambio de salarios por encima de la productividad, empleo estable y paternalismo por parte de los empleadores (Akerlof, 1982; Akerlof y Yellen, 1990).

En otros casos, se diseñan incentivos en forma de "compensación diferida» para motivar al trabajador premiándolo con salarios por encima de su productividad cuando está cerca de la jubilación (Lazear, 1979). Esta compensación diferida aumenta el coste de oportunidad de perder el trabajo y "disciplina» al trabajador disminuyendo el incentivo a reducir su desempeño individual o engañar a sus superiores. El resultado de dicha compensación "diferida» y el pago de salarios crecientes con la edad y la antigüedad es que los trabajadores en mercados internos de trabajo son generalmente mucho menos propensos a abandonar su empleo a favor de otros y tienden a desarrollar largas carreras profesionales dentro de la misma institución. En este contexto, hay que obligar al trabajador a retirarse, para lo cual se establece una edad obligatoria de jubilación. Finalmente, mientras que el salario estaría claramente por encima de la productividad marginal individual en edades avanzadas del trabajador, el modelo de Lazear postula que el salario de entrada podría ser más bajo que la productividad marginal individual (Lazear, 1979: 1.261). En general esperaríamos salarios bajos por debajo la productividad individual en los primeros años de empleo en la empresa y un rápido crecimiento salarial en los trabajadores ya fidelizados.

El propósito del presente artículo es entender el funcionamiento del mercado «interno» de trabajo en Correos de España. Como en otros cuerpos funcionariales del Estado, el mercado interno de trabajo en Correos estaba sometido a unas reglas estrictas de promoción interna a la que se accedía después de superar un examen de oposición muy completo con exámenes de aritmética, francés, gramática castellana y cuestiones asociadas a Correos y su legislación, y que tuvieron su expresión principal en el escalafón de funcionarios del cuerpo de Correos. Es importante señalar que lo que vamos 
a analizar aquí se refiere al llamado Escalafón de Funcionarios del Cuerpo de Correos, pero excluye a la gran masa del llamado personal subalterno y auxiliar, que incluye conductores, carteros o peatones de ese servicio, sobre quienes la documentación es muy limitada. En estos casos, la normativa sólo contemplaba que los aspirantes se licenciaran del Ejército o de la Armada sin nota desfavorable, tuvieran entre 18 y 45 años y demostraran saber leer y escribir (Galvarriato, 1920: 29).

Nuestra fuente principal será el Escalafón de Funcionarios del Cuerpo de Correos publicado anualmente con información sobre el nombre, la fecha de nacimiento, la categoría profesional y los años pasados en esa categoría de todos los funcionarios del cuerpo. Podemos tener una idea de la evolución profesional de los funcionarios del cuerpo siguiendo al mismo individuo por los varios escalafones en los que lo hemos podido localizar (que van, ininterrumpidamente, de 1902 a 1921) y usando también la información sobre los años en cada categoría profesional. Un problema importante es que necesitaríamos un arco temporal algo más largo para observar a los funcionarios a lo largo de todo su ciclo vital y poder observar carreras laborales completas, que es lo que sería aconsejable según la teoría. Sin embargo, quizá tengamos un número de años suficiente para hacernos una idea de las dinámicas internas del funcionamiento del cuerpo. Por otra parte, los escalafones, a diferencia de los expedientes de personal de grandes empresas, no contienen información sobre el salario; aunque podemos imputar fácilmente un salario a cada categoría con las escalas salariales que se pueden encontrar en Villacorta Baños (1989).

La funcionarización del cuerpo en 1873 y 1889, y la evolución del contrato colectivo que regulaba las condiciones de trabajo de los funcionarios de Correos se ha estudiado en detalle en estudios previos (Martínez Lorente, 1993; Villacorta Baños, 1989). El propósito de la presente contribución es intentar comprender el funcionamiento de ese mercado y analizar la evolución de las magnitudes principales como el empleo y los salarios medios y por categorías laborales, así como la evolución de los ingresos y promociones a lo largo del ciclo vital. Respecto a las categorías, analizaremos la evolución y maduración del sistema de empleo en Correos, las carreras de sus directivos, los traslados y las bajas que se producían en el Cuerpo.

Una de las conclusiones principales de este trabajo es que con la extinción del sistema de cesantías a finales del siglo XIX y con la expansión del cuerpo en el siglo XX, la carrera de los funcionarios en el cuerpo de Correos se hizo más atractiva y predecible, lo que contribuyó seguramente a alinear en gran medida los incentivos de los funcionarios en la dirección de un servicio relativamente eficaz y moderno, aunque seguramente mejorable. En este sentido, España siguió sin excesivo rezago las experiencias pioneras de Prusia y Suecia en el siglo XVIII, seguidas por las reformas en el Reino Unido a partir de 1855 y de Estados Unidos a partir de 1883, así como la creación de la Unión Postal Internacional en 1874 (Naím, 2015: 41). Bien es cierto que en 
términos del número de funcionarios de Correos por habitante o en número de oficinas por habitante estaba, con Portugal, muy lejos de experiencias pioneras como el Reino Unido o Suiza e incluso bastante por detrás de Italia (Galvarriato, 1920: 49-50). Esta mejora de las perspectivas profesionales de los funcionarios tuvo sin embargo algún inconveniente. El principal, dada la rigidez de las escalas salariales, los sueldos de los funcionarios eran muy rígidos al alza con lo que la inflación elevada de los años de la Primera Guerra Mundial erosionó seriamente su capacidad de compra. Sin embargo, se desprende de la información recopilada aquí que la acción colectiva destinada a contrarrestar la inflación a partir de 1917 consiguió aumentar los salarios nominales sustancialmente y consiguió aumentar las plazas en las categorías superiores dando lugar a promociones bastante generalizadas.

El artículo está organizado de la siguiente manera. La segunda sección analizará la evolución del empleo en Correos en el tiempo, especialmente en relación con la expansión del uso de servicios postales por parte de la población española y con la evolución de la retribución media y por categorías hasta 1935. Veremos, en este caso, como la aparición de la acción colectiva por parte de los funcionarios a partir de 1917 tuvo un impacto considerable sobre el salario medio. En la tercera sección, discutiremos la evolución del salario a lo largo del ciclo vital y los determinantes de las separaciones entre trabajador y empresa, usando una muestra aleatoria de funcionarios de Correos. En la cuarta sección, estudiaremos la evolución de las promociones, especialmente de los equipos directivos, y analizaremos los traslados. La sección quinta concluye.

\section{LA EVOLUCIÓN DEL EMPLEO Y DEL SALARIO EN CORREOS}

A partir de mitad del siglo XIX y la progresiva integración de los mercados con el fin de las Guerras Carlistas, la mejora en las comunicaciones y especialmente la construcción de la red de ferrocarriles, el Estado español entrevió la necesidad de organizar un cuerpo de funcionarios de Correos que garantizara la comunicaciones que debían acompañar al proceso de desarrollo y al asociado mayor volumen de tráfico postal. Las fechas fundacionales de la organización del cuerpo son 1873 y, especialmente, 1889, mientras que la fusión entre los empleados de Correos y los de Telégrafos se realizaría en 1891. Hasta ese momento, el empleo en Correos se veía fuertemente determinado por los vaivenes de la alternancia política, las famosas cesantías, hasta que en 1889 se produciría el blindaje corporativo de los funcionarios de Correos respecto a los partidos en el gobierno. El 12 de marzo de 1889, se creaba mediante decreto el Cuerpo de Empleados de Correos y se aprobaba el reglamento del mismo el 7 de mayo del mismo año. Parece ser que este reglamento era una copia del que se había intentado tramitar durante la Primera República (Martínez Lorente, 1993: 242). En 1891, la fusión con 
Telégrafos en el llamado Cuerpo de Comunicaciones aprobada por decreto por un gobierno conservador desembocaría en una reducción considerable de la plantilla (se realizó un examen a los empleados de Correos con menos de ocho años de antigüedad y 624 fueron expulsados del cuerpo; cf. Martínez Lorente, 1993: 246). Los nuevos funcionarios debían pasar una oposición que incluía Gramática Castellana, Lengua Francesa (lectura y traducción), Elementos de Aritmética, Geografía Postal e itinerarios postales de España, Legislación de Correos, Legislación del Sello y Timbre del Estado, Tarifas nacionales y extranjeras, Contabilidad Especial de Correos (artículo 10 ${ }^{\circ}$, Real Decreto de Constitución del Cuerpo de Correos del 12 de marzo de 1889; Galvarriato, 1920: 30).

Después de una huelga de telegrafistas, la década de 1890 se caracterizó por varias medidas reformistas. Se restablecieron los cuerpos de Correos y Telégrafos y se promulgaron tres reglamentos del personal de Correos entre 1893 y 1898. Durante el gobierno largo de Antonio Maura, en julio de 1909, con Juan de la Cierva como ministro de Gobernación, se aprobó un reglamento orgánico del personal de Correos que estructuró definitivamente el cuerpo en las tres categorías fundamentales de jefes de administración, jefes de negociado y oficiales, eliminando la categoría de «aspirantes» que existía anteriormente (Anuario Postal, 1912: 18). El personal auxiliar de Correos, que no tenía estatuto de funcionario, se componía de «agentes», «conductores contratistas», "carteros urbanos» $\mathrm{y}$ «carteros rurales».

Dadas las limitaciones de las fuentes, no es fácil analizar la evolución total del empleo en Correos, especialmente con anterioridad al siglo XX. Los datos disponibles en las Estadísticas Históricas de España sobre la evolución del personal de la Administración del Estado agregan en principio los empleados en Correos y Telégrafos (Jordana y Ramió, 2005: 973-1.026). Los escalafones, por otra parte, no integran al llamado personal «auxiliar y subalterno». A diferencia de los anuarios de Telégrafos, no existen anuarios postales para todos los años y los anuarios no siempre dan la información que precisamos. Los escalafones del cuerpo de Correos que hemos podido consultar solo dan información del número de funcionarios del cuerpo, no del empleo total en Correos.

Empezamos analizando la información de las Estadísticas Históricas proporcionada por Jacint Jordana y Carles Ramió, que completamos con la información proveniente de los Anuarios Estadísticos de España (Jordana y Ramió, 2005: 1.019). La serie compilada por estos autores tiene un importante agujero entre 1860 y 1909, fechas entre las que no proporcionan datos de empleo. Según estos autores, el empleo en Correos y Telégrafos ascendía a 9.576 empleados en 1860 y sería de 13.195 empleados en 1909, cuando se produce la reorganización del cuerpo de Correos. En 1906, según el Anuario Estadístico, Correos contaría, exclusivamente, con unos 5.500 trabajadores y, en 1908, con cerca de 6.000. Desde 1909, la plantilla creció rápidamente hasta alcanzar los 20.000 empleados hacia 1915, cuando se produce un 
GRÁFICO 1

EVOLUCIÓN DEL EMPLEO EN CORREOS, 1906-1932

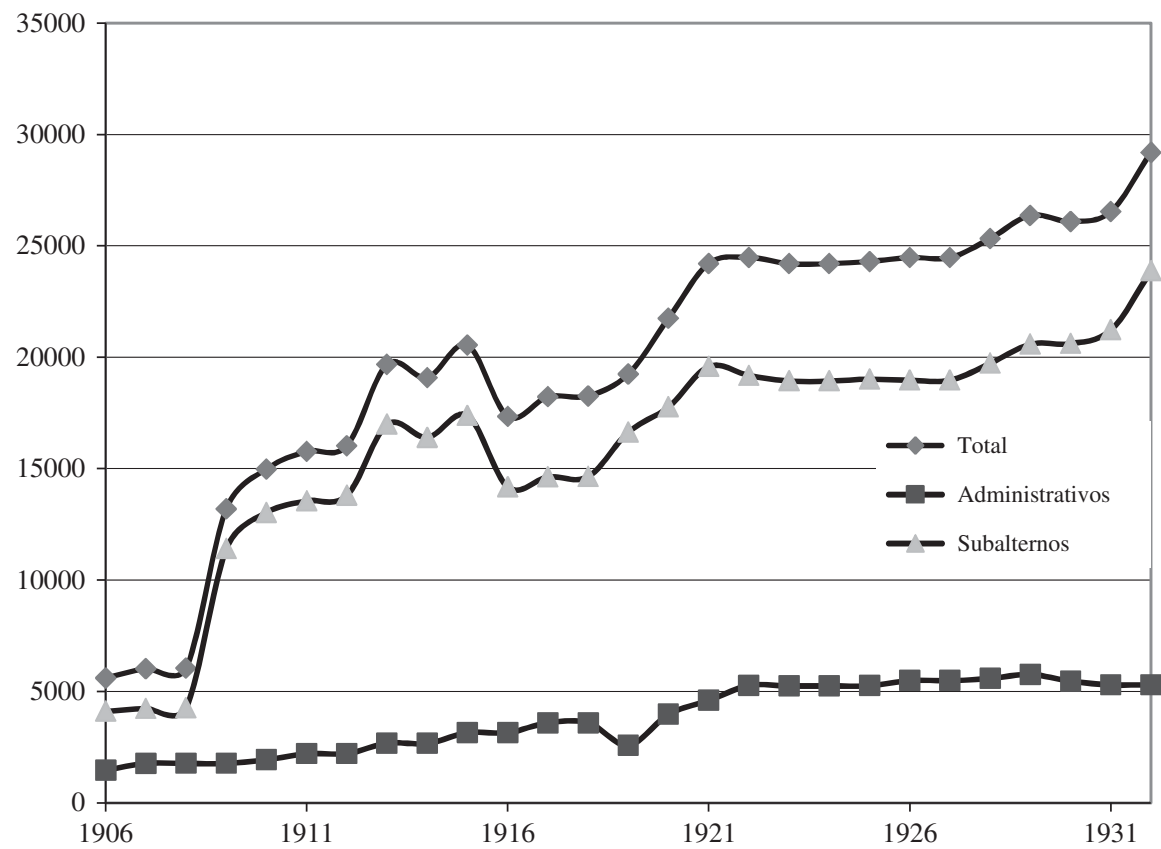

Fuente: Anuario Estadístico de España.

retroceso relativo. A partir de 1920 comienza la recuperación hasta alcanzar los casi 29.000 empleados en 1935, con una mayor concentración de aumento de puestos de trabajo durante los años de la Segunda República. El Gráfico 1 presenta la evolución de la serie de Jordana y Ramió desde 1909, completada por los datos del Anuario Estadístico ${ }^{1}$. Estos datos confirman también que aunque el cuerpo se organizara desde 1889, la expansión principal del empleo en Correos no se produjo hasta la reorganización de 1909. A partir de 1909, en tan solo 20 años, el empleo se duplicó.

Este mismo gráfico también nos permite separar el empleo entre las dos clasificaciones principales de trabajadores, los «administrativos», funcionarios, y el personal auxiliar y subalterno no funcionario. El personal auxiliar, que incluye carteros urbanos y rurales, contratistas de conducciones y los llamados «peatones», y el personal subalterno de la dirección general, las principales administraciones $\mathrm{y}$ las estafetas (ordenanzas, etc.), conformaba el grueso del empleo en Correos y, evidentemente, no estaba

\footnotetext{
1 Anuario Estadístico de España, año 1925-1926, p. 487.
} 
adscrito a los reglamentos de funcionarios del cuerpo de Correos, que determinaban muy precisamente las materias que se sometían a examen de oposición y los mecanismos de promoción. Se observa, en cambio, como el personal funcionario-administrativo tuvo un crecimiento relativamente más lento y continuado (la única ruptura clara es la caída del empleo en 1919, probablemente causada por las represalias del gobierno hacia alguna huelga o el movimiento juntista de 1917-1918).

¿Qué decir de la composición del empleo por género? Contrariamente a lo que sucedió con los telegrafistas, la información de la que disponemos sugiere que el empleo femenino fue inexistente en Correos hasta la llegada de la Segunda República. En los escalafones, no he detectado la presencia de ninguna mujer entre 1902 y 1921 a pesar de que la ley de bases de 1909 hacía posible el empleo de mujeres en Correos (Martínez Lorente, 1993: 247; Anuario Postal, 1912: 18). Sería en 1922 cuando se admite a 300 mujeres, inicialmente para reemplazar a funcionarios huelguistas, aunque al final se les concedió plaza de funcionaria tras un examen (Bordes, 2001: 243). En 1931, había ya 350 «auxiliares femeninos» (sic) (Martínez Lorente, 1993: 249).

¿Hasta qué punto estuvo acompasada la evolución del empleo en relación con el incremento de tráfico postal en España? De nuevo, los datos provienen del Anuario Estadístico, que informa sobre el número total de empleados y la evolución del número de objetos postales tramitados en España (lo que incluye el tráfico interno y con el extranjero). El Gráfico 2 presenta la evolución del número de «objetos postales» que pasaban por Correos por trabajador empleado, por trabajador funcionario-administrativo empleado y por trabajador subalterno-auxiliar empleado. En todos los casos, se observa claramente como la reorganización del servicio durante el gobierno largo de Maura intentó mitigar la más que posible inadecuación de la plantilla al tráfico postal de la época, probablemente provocada por los problemas presupuestarios del gobierno a finales del siglo XIX.

En el caso del personal auxiliar, se redujo el tráfico postal por empleado en un $75 \%$ y, en el caso del personal administrativo-funcionario, en un $40 \%$. Hay algunos picos en las series de tráfico per cápita, especialmente en 1919, cuando se reduce de forma excepcional el número de empleados administrativos funcionarios por las medidas disciplinarias tomadas contra huelguistas (se pasa de 3.602 a 2.597 empleados). El pico observado en 1927 se debe a un incremento inusual del tráfico postal durante ese año (debido, principalmente, a un número anormalmente alto de objetos postales circulados en el interior de España, que podría ser un error o un outlier que se repite, a partir de 1927, en todos los Anuarios Estadísticos). A pesar de estas fluctuaciones, la tendencia de la serie de tráfico postal por empleado es muy negativa en los primeros años de la serie presentada, lo que sugiere que, probablemente, el tamaño de la plantilla era, hasta 1909, insuficiente para el volumen de tráfico postal que tenía España (de ahí que fueran 
GRÁFICO 2

TRÁFICO POSTAL POR EMPLEADO DE CORREOS, 1906-1932

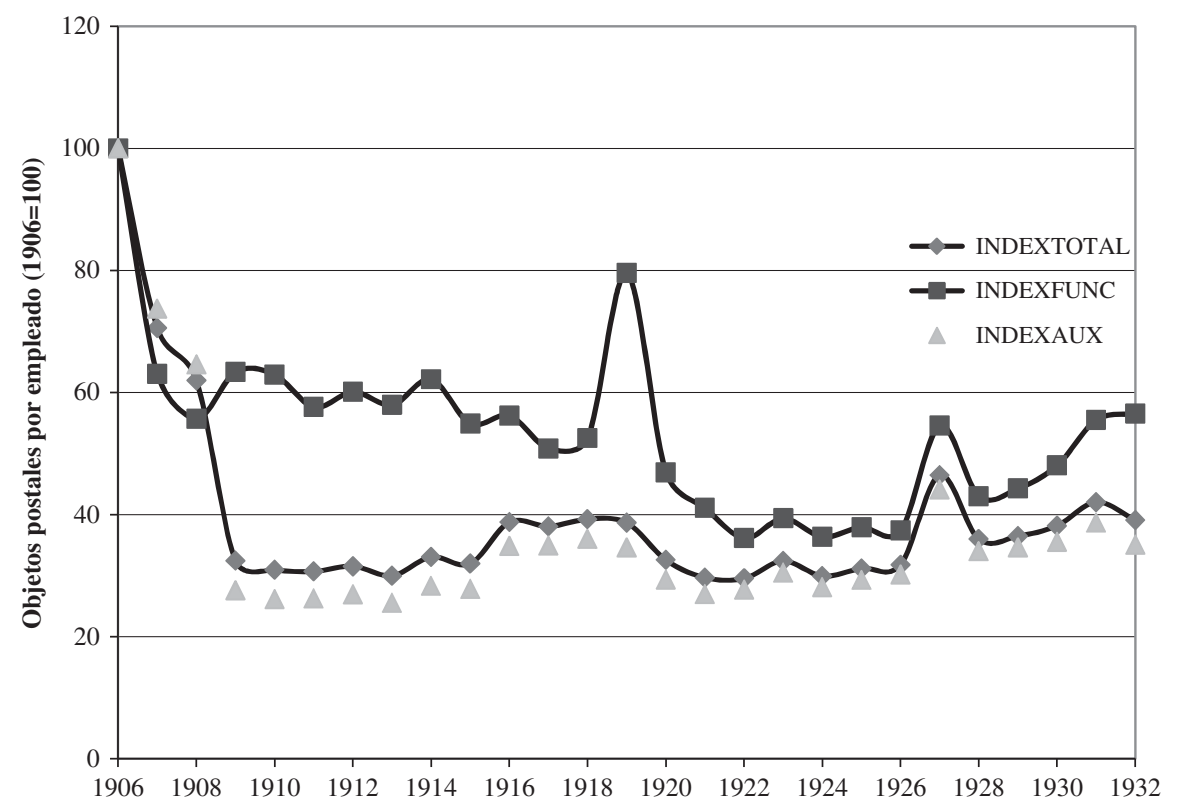

Fuente: Anuario Estadístico de España.

compresibles las quejas sobre la poca fiabilidad del servicio durante la segunda parte del siglo XIX). Después se estabiliza la situación hasta la dictadura de Primo de Rivera, cuando se percibe un ligero incremento del tráfico postal por empleado y, luego, durante la Segunda República, una incipiente reducción.

En este sentido, parece poco discutible que entre 1889 y 1909 el crecimiento del cuerpo estuvo sometido a severas limitaciones presupuestarias. Como veremos más adelante, al existir una tasa muy pequeña de separaciones de los funcionarios, la edad media por categoría creció considerablemente a lo largo del tiempo. Hacia 1909, la edad media de los funcionarios encuadrados en gran parte de las categorías profesionales superaba los 50 años. En este contexto, la distancia entre la edad promedio de los que sacaban las oposiciones y la edad en la que se obtenía la primera plaza aumentaba. En 1895, los opositores podían esperar casi veinte años hasta convertirse en oficiales de quinta; en 1909, la edad promedio de los opositores que esperaban una plaza era solo cinco años menor que la de los oficiales de quinta, seguramente porque se asimiló a una gran cantidad de opositores con derecho a plaza. En la siguiente categoría, la edad promedio 
es de casi 40 años, y en la siguiente de más de 50. Durante la enorme expansión del cuerpo (de casi un 100 \%) entre 1909 y 1921, las edades promedio en cada categoría se vuelven mucho más razonables teniendo en cuenta la esperanza de vida de la época. Antes de la expansión del servicio. Antes de la expansión del servicio a principios del siglo XX, convertirse en funcionario de Correos era una inversión gigantesca con un rendimiento incierto y muy tardío, hacia los 40-50 años. A partir de 1909, con el crecimiento del servicio, entrar en Correos parece una carrera profesional más razonable, en la que se accedía a puestos de funcionario en la veintena y a partir de los cuarenta si era puestos directivos.

Respecto a la evolución del salario en el tiempo, disponemos sobre todo de la referente al personal funcionario según las distintas escalas que se fueron aprobando sucesivamente; en cambio, es imposible conocer los sueldos del personal auxiliar o subalterno. Concretamente, usamos los convenios salariales rastreados por Francisco Villacorta Baños en la Gaceta de Madrid (Villacorta Baños, 1989: 219), que en algunos casos también se pueden comparar con la escala salarial de 1890 (Martínez Llorente, 1993: 241), y los anuarios postales que hemos podido consultar. Por otra parte, los escalafones no tenían el propósito de especificar los salarios y en ellos es imposible encontrar información sobre las retribuciones de cada categoría profesional y su evolución en el tiempo.

Con las escalas salariales de 1876-1877, 1900, 1911, 1919, 1921 y 19221923 podemos reconstruir la evolución del salario nominal medio para los empleados administrativos del cuerpo. Aquí nos hemos visto obligados a usar las cifras de empleo relativo en cada categoría que ofrece Villacorta Baños para cada corte y a proyectarlos hasta el siguiente corte. Para deflactar el salario nominal hemos usado los índices de coste de la vida agregados para toda España de Leandro Prados de la Escosura (2005, pp. 545-547, para el deflactor implícito del consumo privado) y de Jordi Maluquer de Motes (2005). La principal discrepancia entre los índices es la evolución de los precios al consumo a finales del siglo XIX, período en el que el índice de Prados de la Escosura es notablemente menos inflacionario que el de Maluquer de Motes. La consecuencia es que, como los salarios nominales no se ajustaban a la baja (se mantenían estables entre una escala salarial y la otra), el salario real habría aumentado a finales del siglo XIX si se usa el índice de Prados de la Escosura, pero habría crecido menos si se usa el índice de Maluquer de Motes. Este efecto también se traslada, en parte, a la primera y segunda décadas del siglo XX, cuando el salario real sería más alto en el caso de usar el índice de precios de Prados de la Escosura. En ambos casos, se percibe un serio deterioro de la capacidad de compra del salario a partir de 1911, que se acentúa durante los años de la primera guerra mundial hasta que en 1917 se alcanza el nivel más bajo del salario real de toda la serie. En ambas series, el salario real de 1917 es, aproximandamente, un 5\% inferior al salario real de 1876, una situación a todas luces inaceptable para 
TABLA 1

EDAD PROMEDIO Y PORCENTAJE DEL TOTAL DE EMPLEADOS POR CATEGORÍA PROFESIONAL, 1895-1921

\begin{tabular}{|c|c|c|c|c|c|c|c|c|}
\hline \multirow[b]{2}{*}{ Categoría } & \multicolumn{2}{|c|}{1895} & \multirow{2}{*}{$\begin{array}{c}1902 \\
\%\end{array}$} & \multicolumn{2}{|c|}{1909} & \multirow{2}{*}{$\begin{array}{c}1915 \\
\%\end{array}$} & \multicolumn{2}{|c|}{1921} \\
\hline & $\%$ & $\begin{array}{c}\text { Edad } \\
\text { promedio }\end{array}$ & & $\%$ & $\begin{array}{c}\text { Edad } \\
\text { promedio }\end{array}$ & & $\%$ & $\begin{array}{c}\text { Edad } \\
\text { promedio }\end{array}$ \\
\hline Jefe adm. $1 .^{a}$ & 0,1 & 60 & 0,1 & 0,04 & 74 & 0,04 & 0,1 & 62 \\
\hline Jefe adm. $2 .^{a}$ & 0,1 & 59 & 0,2 & 0,1 & 60,7 & 0,1 & 0,3 & 60,2 \\
\hline Jefe adm. $3 .^{a}$ & 0,2 & 55 & 0,3 & 0,1 & 57,8 & 0,5 & 0,7 & 57,4 \\
\hline Jefe adm. $4 .^{\mathrm{a}}$ & 0,1 & 49,5 & 0,4 & 0,2 & & - & & 55 \\
\hline Jefe negociado $1 .^{a}$ & 0,5 & 56,5 & 0,9 & 0,5 & $\mathbf{5 7 , 5}$ & 0,7 & 1,4 & 50,1 \\
\hline Jefe negociado $2 .^{a}$ & 1 & 56 & 1,4 & 0,8 & 56,9 & 1,1 & 2,3 & 48,3 \\
\hline Jefe negociado $3 .^{\mathrm{a}}$ & 1 & 51,7 & 1,9 & 1,2 & 56,4 & 1,8 & 4,1 & 43,7 \\
\hline Oficiales $1 .^{\mathrm{a}}$ & 3,3 & 48,6 & 4,1 & 2,6 & 53,8 & 5,6 & 26,1 & 29 \\
\hline Oficiales $2 .^{\mathrm{a}}$ & 4,7 & 52,1 & 6,4 & 4,4 & $\mathbf{5 7}$ & 8,1 & 32,5 & 23,5 \\
\hline Oficiales $3 .^{\mathrm{a}}$ & 7,4 & 50,2 & 10 & 8 & 52,3 & 16,3 & 21,4 & 21,9 \\
\hline Oficiales $4 .^{\mathrm{a}}$ & 11 & 47,1 & 15,2 & 12 & 39,8 & 31,5 & - & - \\
\hline Oficiales 5. & 17,4 & 41,8 & 24,6 & 41,2 & 27,56 & 34 & - & - \\
\hline Aspirantes 1. ${ }^{\mathrm{a}}$ & 22,7 & 35,2 & 22,6 & - & - & - & - & - \\
\hline Aspirantes 2. ${ }^{\mathrm{a}}$ & 15,3 & 24,3 & 12 & - & - & - & - & - \\
\hline $\begin{array}{l}\text { Opositores «expectantes» de } \\
\text { plaza }\end{array}$ & 15,25 & 23,4 & - & 28,8 & 22,7 & - & 11,2 & 21,8 \\
\hline Total empleados & 1.095 & & 1.135 & 2.497 & & 2.752 & 4.722 & \\
\hline
\end{tabular}

Fuente: Escalafones del Cuerpo de Funcionarios de Correos. 
GRÁFICO 3

EVOLUCIÓN DEL PROMEDIO DEL SALARIO REAL EN EL CUERPO DE CORREOS, 1876-1923

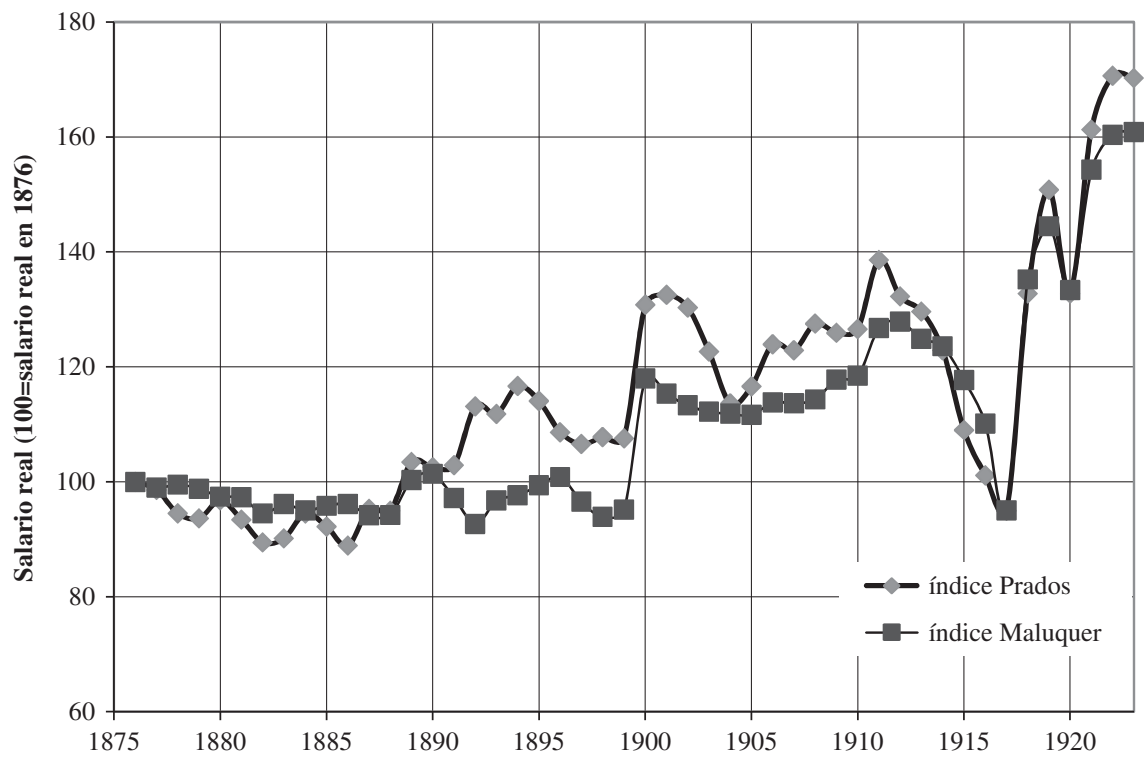

Fuentes: Villacorta Baños, Profesionales y burócratas (1989), p. 219; Estadísticas Históricas de España, vol. III, pp. 1.290-1.291.

los trabajadores del cuerpo. A partir de ahí, sin embargo, se produce una notable mejora del salario medio, con una leve recaída en 1920. Como consecuencia, en 1922, el salario real medio es entre un 60 y un $70 \%$ superior al salario real medio de 1876.

Sin embargo, visualizar la evolución del salario real promedio ponderado no hace justicia a las variaciones significativas que se perciben en la evolución del salario de las distintas categorías profesionales. El siguiente gráfico analiza la evolución en el tiempo del salario medio real para las categorías más baja y más alta de oficiales, la de jefe de negociado de segunda y la de jefe de administración de primera. El análisis de esta evolución muestra cómo, durante los años de la primera guerra mundial, se produjo una compresión considerable de los diferenciales salariales dentro del escalafón, cuando las nuevas escalas salariales beneficiaron claramente a las categorías inferiores (desaparición de las categorías de oficial de cuarta y quinta clase y crecimiento del sueldo de la categoría más baja). Especialmente, en el caso de las categorías superiores: la movilización de los años 1918-1919 erosionó mucho la posición relativa de los puestos directivos dada la compresión de 
GRÁFICO 4

SALARIO REAL POR CATEGORÍAS DEL ESCALAFÓN, 1876-1922

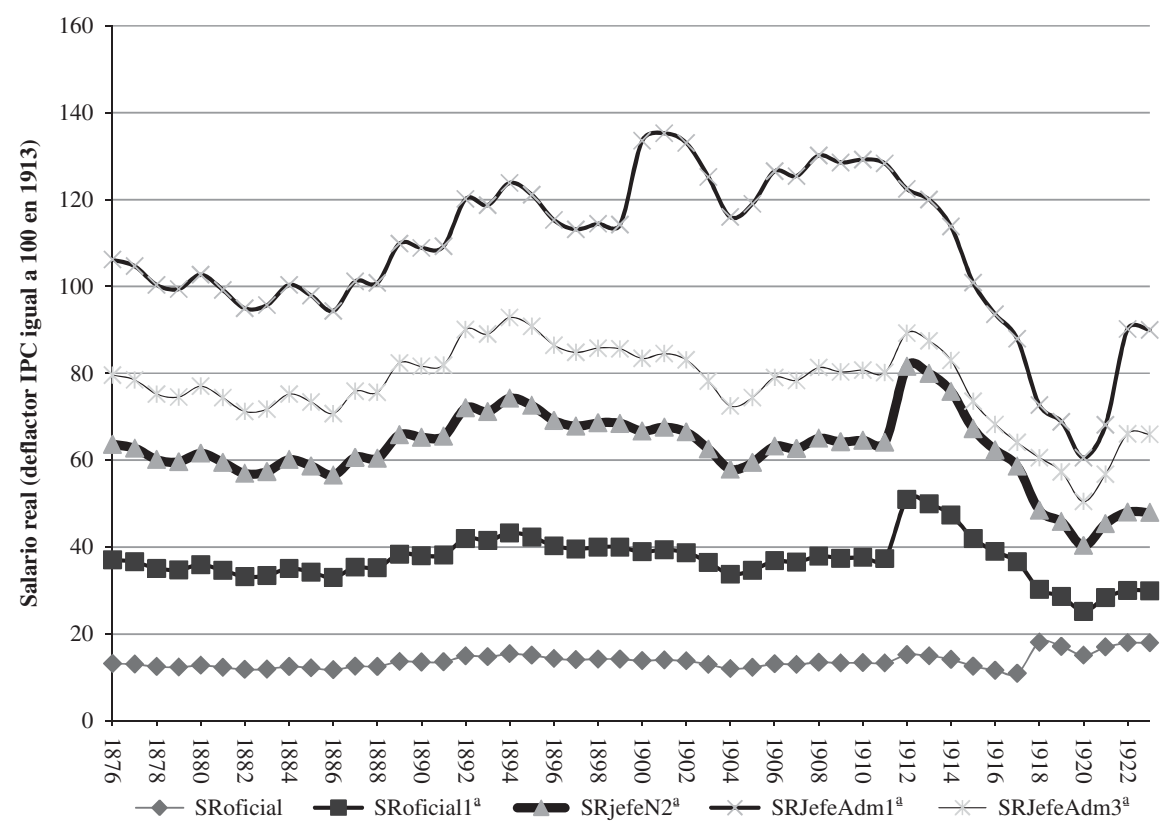

Fuentes: salarios de Villacorta Baños, Profesionales y burócratas (1989), p. 219; deflactor IPC de Estadísticas Históricas de España, vol. III, pp. 1.290-1.291.

los diferenciales salariales; por otra parte, algo típico de los sistemas de contratación colectiva que surgieron en las décadas de 1920 y 1930 (Goldin y Margo, 1992).

\section{SALARIOS, EXPERIENCIA Y CICLO VITAL}

En esta sección analizamos la evolución laboral y salarial de un trabajador administrativo funcionario usando información de los escalafones en los años 1899 y 1921. Esta perspectiva nos da información sobre la evolución en el tiempo del salario a medida que el funcionario va acumulando experiencia. Con este propósito, hemos reunido información sobre la evolución de las categorías profesionales de una muestra de 150 individuos del escalafón (muestreado aleatorio usando la primera letra de su apellido) que se encontraban en las categorías inferiores al principio de nuestro período; esto es, eran aspirantes de segunda, aspirantes de primera $\mathrm{u}$ 
oficiales de quinta entre 1899 y 1902 (el primer escalafón del que disponemos datos es el de 1902, pero podemos extraer información retrospectiva hasta 1899).

Lo primero que nos permite la muestra es observar la evolución de la edad promedio de esta cohorte a medida que va accediendo a cada una de las categorías profesionales en el escalafón del cuerpo. La Tabla 2 presenta dicha evolución con la desviación estándar y las edades mínimas y máximas de los funcionarios de esa cohorte en cada categoría. La evolución de la edad promedio en cada categoría para esta cohorte entre 1899 y 1902 contrasta con la evolución de la edad promedio por categoría cuando la calculamos usando la muestra completa (presentada en la Tabla 1). En este caso, esta cohorte va progresando en el escalafón a edades relativamente tempranas en comparación con el grueso de dicho escalafón. La razón principal podría ser que la expansión del cuerpo pudo beneficiar a unas cohortes mucho más que a otras, especialmente en lo que respecta a la transición desde que se ganaba el derecho a una plaza después de opositar a ella, que para algunas cohortes anteriores debió de ser particularmente larga. En este caso, en la cohorte del período 1899-1902, parece que dicha transición se hizo con relativa rapidez.

La progresión entre aspirantes y oficiales y en las categorías de oficial era automática por antigüedad, después requería el examen de ampliación descrito en la sección previa para poder acceder a las categorías de «jefe de negociado» y «jefe de administración». El gráfico siguiente traza la evolución del salario real para los 150 individuos de la cohorte entrante entre 1899 y 1902. Aunque hay mucha variación alrededor de cada edad, la tendencia

TABLA 2

EDAD MEDIA POR CATEGORÍA PROFESIONAL, COHORTE ENTRANTE EN 1899-1902

\begin{tabular}{|l|c|c|c|c|}
\hline Categoría & Media & $\begin{array}{c}\text { Error } \\
\text { estándar }\end{array}$ & $\begin{array}{c}\text { Trabajador más } \\
\text { joven }\end{array}$ & $\begin{array}{c}\text { Trabajador de mayor } \\
\text { edad }\end{array}$ \\
\hline Aspirante 2. & 26 & 0,34 & 14 & 47 \\
Aspirante 1. $^{\mathbf{a}}$ & 28,7 & 0,27 & 17 & 49 \\
Oficial 5. $^{\mathbf{a}}$ & 32 & 0,2 & 19 & 53 \\
Oficial 4. $^{\mathbf{a}}$ & 36,1 & 0,21 & 23 & 56 \\
Oficial 3. & 40 & 0,21 & 27 & 61 \\
Oficial 2. & 44 & 0,22 & 33 & 64 \\
Oficial 1. & 47,1 & 0,28 & 32 & 57 \\
Jefe adm 3.a & 48,7 & 0,54 & 39 & 58 \\
Jefe adm 2.a & 51,9 & 0,78 & 45 & 59 \\
Jefe adm 1.a & 52 & 2 & 50 & 54 \\
\hline
\end{tabular}

Fuente: calculado a partir de los Escalafones del Cuerpo de Funcionarios de Correos. 
media es clara: el salario crecía a medida que el trabajador pasaba más años en el cuerpo y, como solía entrar joven (aunque no siempre muy joven: la edad de entrada está entre los 14 y los 47 años), este salario creciente se correlacionaba positivamente con la edad del trabajador. Una característica es el aumento de la desigualdad salarial en el último tramo de las vidas laborales analizadas aquí, seguramente relacionado con la capacidad de seguir ascendiendo más allá de la categoría de oficial de primera. La línea discontinua recoge el resultado de una regresión de mínimos cuadrados ordinarios entre el salario real y la edad y la edad al cuadrado. Vemos, en este caso, como los ingresos suben con la edad del trabajador y además, típicamente, en consonancia con el mecanismo de compensación diferida típico de mercados internos de trabajo, no se produce una disminución paulatina del salario a medida que el trabajador se va acercando a la edad de jubilación. Consistente con este resultado, en este sistema el empleador tiene que «forzar» al trabajador a retirarse a partir de cierta edad.

Sin embargo, el Gráfico 5 quizá no nos permita tener una visión clara de la evolución del salario a lo largo del ciclo vital de cada trabajador, al mezclarse los salarios de trabajadores que entraron en el cuerpo a edades distintas. En este caso, lo que nos interesa es la evolución individual de los

GRÁFICO 5

EL SALARIO Y LA EDAD DEL TRABAJADOR

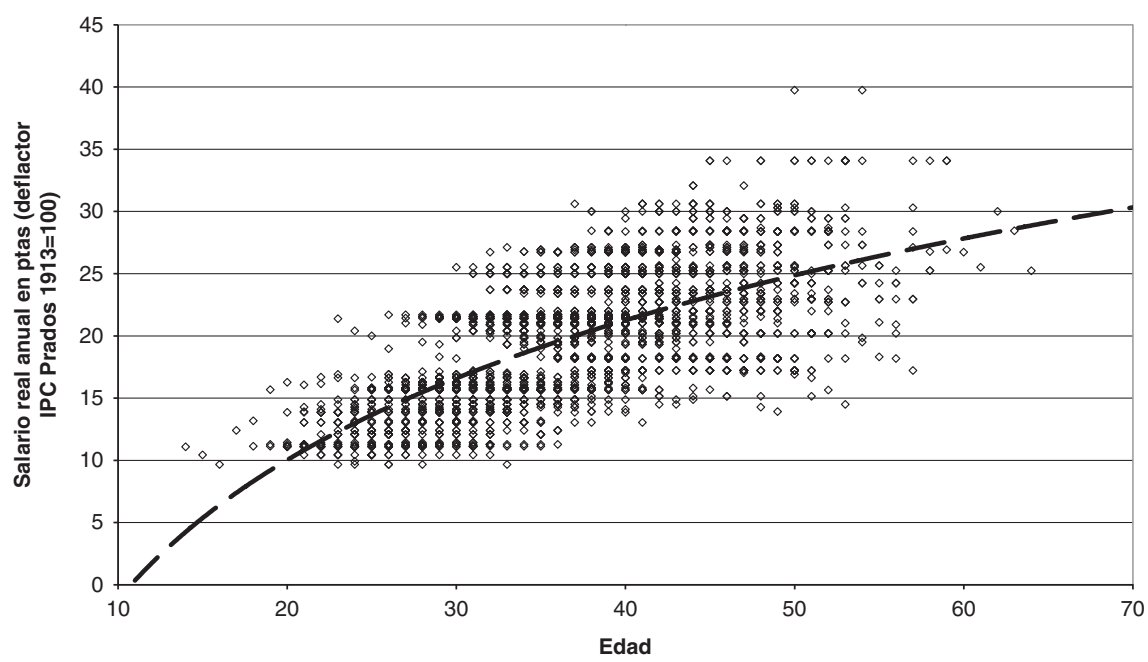

Fuente: calculado a partir de los Escalafones del Cuerpo de Funcionarios de Correos; salarios de Villacorta Baños, Profesionales y Burócratas (1989), p. 219; deflactor IPC de Estadísticas Históricas de España, vol. III, pp. 1.290-1.291. 
ingresos a medida que el trabajador gana experiencia dentro del cuerpo. Los siguientes gráficos muestran la evolución, a lo largo de 22 años, del salario individual nominal y real de un trabajador típico de la cohorte entrante entre 1899 y 1902. Exploramos cinco casos de vidas laborales completas en la muestra de la cohorte 1899-1902 escogidas aleatoriamente. Tenemos casos típicos que van desde situaciones en las que el funcionario no consigue rebasar la oficialidad de primera hasta otras con promociones relativamente rápidas en las que el funcionario alcanza puestos más directivos como el de jefe de administración de primera. Como se desprende del Gráfico 6, los funcionarios accedían al cuerpo entre los veinte y los treinta y pocos años, y tenemos una panorámica continua de la evolución de su salario durante los 22 años siguientes en el cuerpo.

El gráfico con la evolución del salario nominal refleja de forma nítida el funcionamiento del escalafón, con promociones internas casi automáticas cada cuatro o cinco años hasta alcanzar puestos de dirección en algunos casos. A partir de 1917, estos ascensos serían ya automáticos hasta jefe de negociado, reservando la mitad de las promociones a jefe de administración a promociones automáticas para los funcionarios con más antigüedad (Villacorta Baños, 1989: 381). En este proceso, el salario nominal se

\section{GRÁFICO 6 \\ SALARIO NOMINAL Y EDAD DEL FUNCIONARIO DE CINCO FUNCIONARIOS TÍPICOS}

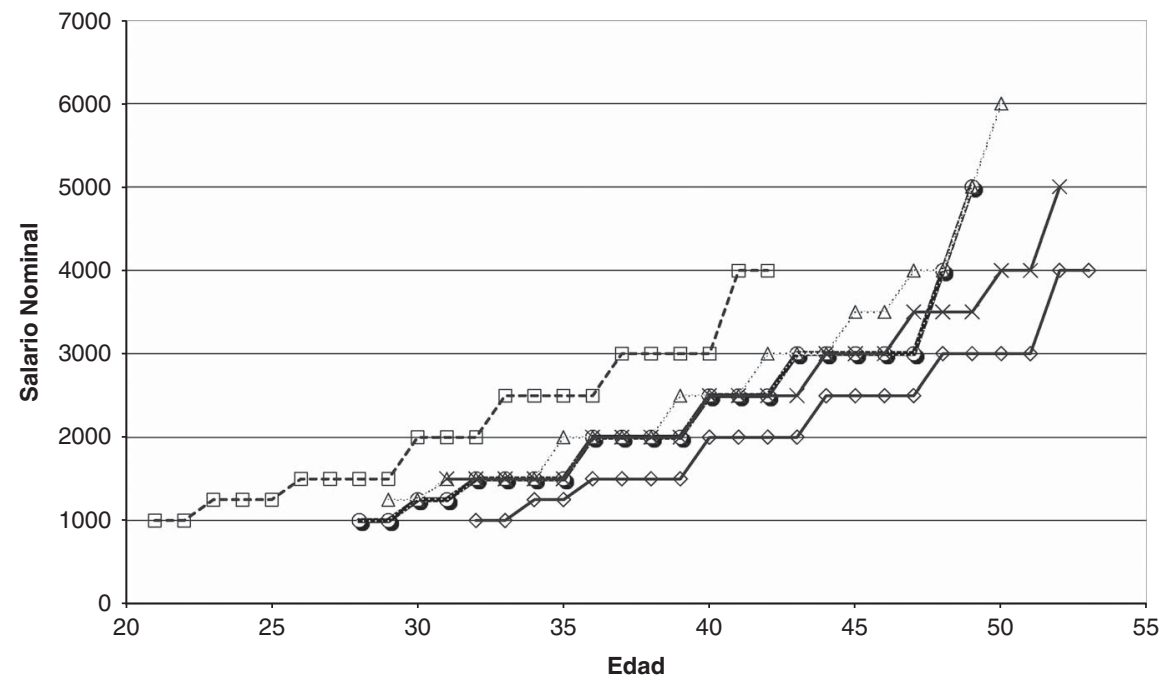

Fuente: calculado a partir de los Escalafones del Cuerpo de Funcionarios de Correos y Villacorta Baños, Profesionales y burócratas (1989), p. 219. 
multiplicaba por cinco o por seis a lo largo de 20 años y no se producía una reducción del salario a medida que el trabajador se acercaba a la vejez, en línea con el modelo de compensación diferida.

Otro elemento en el perfil salarial de los trabajadores que hay que tener en cuenta según la teoría tiene que ver con el salario de entrada. El crecimiento sostenido del salario nominal con las promociones automáticas podría simplemente contrarrestar los muy bajos salarios de entrada de aspirantes y oficiales de las categorías inferiores. Sin embargo, el sueldo anual entrante de los aspirantes, 1.000 pesetas a principios del siglo XX, es comparable, por ejemplo, al de un ordenanza, y algo más bajo que el de la categoría inferior de porteros del Banco de España (Moreno, 2011: 188); es decir, ocupaciones en el sector servicios que no estarían sujetas a las promociones internas típicas de los mercados internos del sector servicios. En esta comparación, el salario de entrada no es particularmente bajo, lo que iría quizá en contra del modelo de Lazear (1979) en lo que respecta a los salarios de entrada. Sin embargo, desde el punto de vista del trabajador, esta comparación no tendría en cuenta los varios años sin ingreso a la espera de pasar la oposición y ocupar una plaza.

También podríamos hacernos una idea del coste de oportunidad de la «espera» de los funcionarios de Correos hasta llegar a salarios relativamente altos si se comparan los salarios de entrada en el cuerpo de funcionarios con el sueldo de ocupaciones en el sector privado que no exigieran el mismo nivel de preparación. El sueldo de entrada de 1.000 pesetas anuales de la cohorte 1899-1902, asumiendo un año laboral con 280 días, correspondía a 3,5 pesetas al día. Este sueldo sería comparable al de un obrero cualificado en la Barcelona de principios de siglo. Por ejemplo, entre los tipógrafos, un oficial cajista ganaba casi 5 pesetas al día (Sastre, 1915: 233); un cochero de ómnibus 4,25 y un conductor 3,25 (Sastre, 1905: 46-47). Dicho esto, el crecimiento del salario nominal en los primeros años de permanencia en el cuerpo de Correos era relativamente lento para la cohorte que estamos analizando, aunque el relativo control de precios de principio del siglo XX ayudó mejorar el poder de compra de estos trabajadores.

El estudio de la evolución del salario real a lo largo del ciclo vital para estos individuos que mostramos en el Gráfico 7 nos obliga a matizar algunas de las conclusiones del análisis de la evolución del salario nominal. La primera es que, a pesar de sueldos nominales relativamente estables, en los primeros años de esta cohorte el salario real mejoró significativamente y alcanzó el pico de ingresos en el año decimotercero o decimocuarto de experiencia en el cuerpo. Estos son años de baja inflación relativa y las mejoras en el salario nominal derivadas de los ascensos de los funcionarios en el escalafón se tradujeron en mejoras sustanciales en el salario real. La mejora en los diez primeros años de experiencia es de alrededor del 100\% (el salario real se dobla a partir del salario inicial).

La segunda consideración es el tremendo impacto de la inflación a partir del estallido de la primera guerra mundial, en la que los miembros del cuerpo 


\section{GRÁFICO 7 \\ SALARIO REAL Y EDAD DEL FUNCIONARIO EN EL CASO DE CINCO FUNCIONARIOS TÍPICOS}

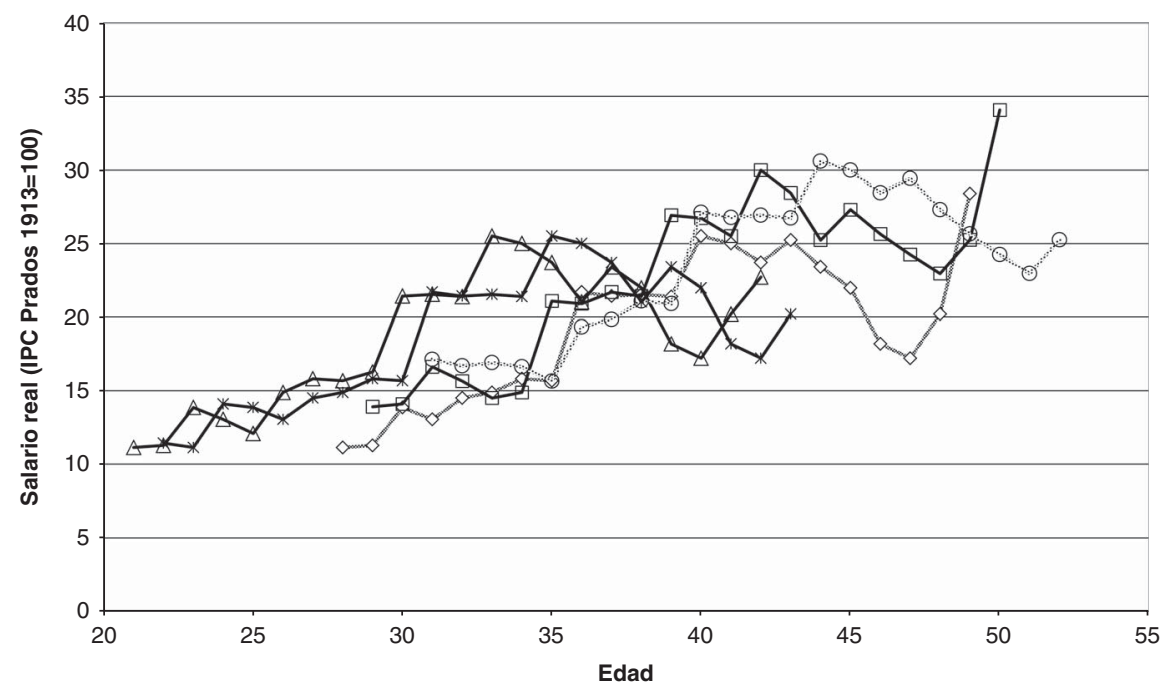

Fuente: calculado a partir de los Escalafones del Cuerpo de Funcionarios de Correos; salarios de Villacorta Baños, Profesionales y burócratas (1989), p. 219; deflactor IPC de Estadísticas Históricas de España, vol. III, pp. 1.290-1.291.

encadenaron ocho años seguidos de pérdidas de poder adquisitivo (que incluyen dos años de inflación moderada en 1912 y 1913); se llegó al punto más bajo en 1919. Para los trabajadores que hemos usado en el gráfico, esto significó pérdidas de poder adquisitivo importantes. También es muy significativo, sin embargo, el crecimiento del salario real a partir de 1919, con importantes incrementos en 1920 y en 1921 causados por el aumento de los sueldos nominales y la deflación. Aun así, en 1920, los funcionarios que estudiamos aquí todavía no habían superado el poder de compra que tenían diez años antes. De hecho, solo superan el salario real anterior a los años de la crisis los que consiguen promocionarse a posiciones directivas (Jefe de Negociado).

En conclusión, el análisis de la evolución del salario nominal y real de los individuos de la cohorte entrante entre 1899 y 1902 se sitúa perfectamente dentro del marco de un mercado interno de trabajo, muy rígido en lo que respecta a promociones internas dentro del cuerpo. En este sentido, el trabajador, una vez superado el examen de oposición y cuando se abría la plaza, podía esperar un crecimiento sostenido y considerable de sus ingresos nominales a medida que iba subiendo puestos en el escalafón. El perfil de los ingresos nominales era una curva creciente con la experiencia y la edad, en concordancia con el típico modelo de compensación diferida de la literatura. 
Dos factores eran importantes en la progresión salarial de los funcionarios. El primero es el crecimiento del salario nominal dependía de promocionarse a posiciones directivas, algo que se hizo más automático a partir de 1917, sobre todo con la expansión de los puestos directivos mencionada más arriba. El segundo es la inflación que, al menos hasta 1920, erosionó de forma muy considerable el poder de compra de los salarios. En este sentido, quizá los costes de transacción de renegociar la escala salarial de los funcionarios causaron que el salario nominal fuera rígido no solo a la baja en períodos de deflación, sino también al alza en períodos inflacionarios. La mayor organización y más eficiente acción colectiva de los funcionarios durante los años de la primera guerra mundial es perfectamente comprensible dado el contexto inflacionario de ese período. La evidencia histórica sugiere que, en general, esa movilización fue exitosa y condujo a la corrección de los salarios nominales y a promociones bastante generalizadas dentro del escalafón.

Los perfiles salariales muestran sueldos no excesivamente bajos al inicio de la carrera laboral y aumentos casi automáticos del salario nominal hasta la jubilación voluntaria a los 60 u obligatoria a los 65 años (Galvarriato, 1920: 30). Estos perfiles salariales serían compatibles con los mecanismos de compensación diferida de la literatura de mercados internos de trabajo, con la excepción de los salarios de entrada en los modelos de compensación diferida en los que el salario inicial está por debajo de la productividad individual (aunque para el empleado sí que hay varios años de ingresos bajos anteriores a la entrada en Correos). Uno de los propósitos de esta compensación diferida era disciplinar a los funcionarios en un contexto en el que es muy difícil para el empleador (en este caso, el Estado) observar el desempeño individual de cada trabajador. En este sentido, un elemento típico de los reglamentos era la organización de tribunales de honor para resolver problemas de disciplina (Reglamento Orgánico del Personal de Correos de 11 de junio de 1909, base cuarta) (Galvarriato, 1920: 33). La posibilidad de medidas disciplinarias que llevaran al despido y la pérdida de esa compensación diferida que recibiría el trabajador cuando es mayor y más vulnerable es la que en principio actúa como elemento disciplinador del funcionario. Hasta qué punto funcione el control disciplinario, qué protección tenga el trabajador frente al despido y el tamaño de la compensación diferida es lo que en estos modelos determina finalmente el nivel de esfuerzo del trabajador.

\section{DINÁMICAS INTERNAS DEL ESCALAFÓN DE FUNCIONARIOS: SEPARACIONES, PROMOCIONES Y TRASLADOS}

\subsection{Separaciones}

En este apartado analizaremos la evolución de elementos importantes en las carreras profesionales de los funcionarios del cuerpo. Las rupturas o 
separaciones del cuerpo serían el evento principal en la carrera laboral de los funcionarios. Estas separaciones se podrían deber a expulsiones o depuraciones por problemas disciplinarios, jubilaciones, muertes o enfermedades o cambio de empleador. La evidencia de la cohorte que estudiamos (la entrante en 1899-1902) demuestra el considerable apego a la carrera funcionarial de los que aprobaban la oposición. Durante 20 años rastreamos la evolución del empleo en el tiempo y vemos como la tasa de separación es extraordinariamente baja para el período. A lo largo de 20 años, la probabilidad estimada de separación del cuerpo se reducía a solo un $20 \%$. Nuestro muestreo de las causas de la movilidad del personal (que después analizaremos para el caso de los traslados) muestra una inexistente o muy baja presencia de separaciones causadas por motivos disciplinarios.

Para estimar esa probabilidad, generamos un modelo de duración en tiempo discreto en el que la probabilidad de permanecer en el cuerpo de los 150 funcionarios que hemos seleccionado de la cohorte entrante de 18991902 depende del tiempo transcurrido. La variable dependiente en este contexto toma valor 1 mientras el funcionario está en activo y 0 si abandona el cuerpo (sin especificar las causas de ese abandono). Es importante señalar que, al empezar con una cohorte entrante, es muy poco probable que un funcionario salga del cuerpo por una jubilación voluntaria u obligatoria. Aparte del tiempo, como variables explicativas podemos considerar la edad y la categoría profesional. Sin embargo, estas variables están muy correlacionadas con el tiempo transcurrido. Cuando incluyo esas variables, consigo un aumento muy limitado del poder explicativo del modelo a costa de diluir la significancia de los coeficientes de las variables del modelo ampliado. Debido a que los resultados negativos (separaciones) aparecen en mucha menor cantidad que los positivos, estimo un modelo cloglog (complementary log-log model) y después calibro la probabilidad de seguir empleado en función del número de años desde que empieza a contar el tiempo del modelo de duración.

Con los resultados de estas regresiones, podemos estimar la probabilidad individual media de seguir empleado en cada año transcurrido: en 20 años, la probabilidad cae algo más del $20 \%$. Esto significa una tasa de separaciones escasamente superior al $1 \%$ anual para la cohorte estudiada (lo que supone que se necesita reponer un trabajador de cada cien empleados al principio del año). ¿Podría corresponderse esta tasa de separaciones simplemente al ritmo de fallecimientos en el cuerpo? Nuestros cálculos sugieren que no. La estimación de 1910-1911 de las tasas de mortalidad para todo el cuerpo se situaría alrededor del 3,2 \%o (Anuario Postal, 1912), aunque debería ser algo más baja para una cohorte entrante. Esta tasa es notablemente más baja que la tasa de separaciones anual. Lo que, a su vez, sugiere que las separaciones se produjeron, mayoritariamente, por la llamada «no presentación», que suponemos consistía en no presentarse en un destino determinado al obtener la plaza o al ser trasladado, o por una de las muy raras medidas disciplinarias 
TABLA 3

LA PROBABILIDAD DE SEGUIR EMPLEADO EN LA COHORTE DE 1899-1902. DOS MODELOS DE DURACIÓN

\begin{tabular}{|l|c|c|}
\hline & Cloglog & Logit \\
\hline ln (tiempo) & $-0,62(0,05) * * *$ & $-1,67(0,16) * * *$ \\
Constante & $2,38(0,14)^{* * *}$ & $6,47(0,43) * * *$ \\
\hline $\mathbf{N}$ & 3090 & 3090 \\
$\chi^{2}$ & $175 * * *$ & $174 * * *$ \\
\hline
\end{tabular}

Nota: error estándar entre paréntesis, *** significativo al $1 \%, * *$ significativo al $5 \%$.

conducentes a la expulsión del cuerpo (por ejemplo, en 1910 o 1911 no se encuentran casos de este tipo de medidas). A pesar de que la tasa de separaciones es notablemente superior a la tasa de mortalidad en el cuerpo, una tasa de separación del $1 \%$ anual de promedio para esta cohorte sigue siendo muy baja en comparación con los mercados internos de empresas industriales del período. Aunque no existen demasiados estudios al respecto, una empresa textil con trabajo masculino en el siglo XIX en Inglaterra tenía una tasa de separaciones del $22 \%$ (Leunig, 2003). En el caso de una gran empresa del textil en Barcelona con presencia mayoritaria de trabajo femenino, la tasa anual de separaciones era casi del 80\% (Domenech, 2008: 17).

Quizá un elemento clave en esta tasa de separaciones tan baja es el recurso a las licencias ilimitadas por parte de los funcionarios. Por ejemplo, usando el escalafón de 1909, podemos calcular que, alrededor de un 6,5\% de los funcionarios se encontraban en situación de "licencia ilimitada». Dado que una parte importante de los funcionarios en licencia ilimitada lo fueron durante varios años, eso significaría que el número anual de funcionarios del cuerpo que pedían licencia ilimitada en un año determinado era relativamente bajo. Incluso aceptando un número bastante alto en el que tres de cada cien funcionarios pidieran la licencia anualmente, esto aún significaría que las tasas de separación, alrededor del $4 \%$, eran extremadamente bajas en comparación con los pocos ejemplos de los que disponemos en el sector privado. Sin embargo, estarían en línea con las estimaciones de la tasa de separaciones provenientes de grandes empresas de servicios, como los bancos, en economías desarrolladas — por ejemplo, Seltzer y Simons (2001: 212) estimaron una tasa de separaciones del 6,3\% para un gran banco australiano a finales del siglo XIX y principios del siglo XX.

\subsection{Promociones}

Si pasamos a analizar la evolución de las posibilidades de promoción en el cuerpo, vemos que las de cada cohorte dependían de la expansión de 
Correos y que una promoción fluida entre categorías solo se consiguió gracias a la expansión del cuerpo de funcionarios a partir de la reforma de 1909. La Tabla 4 recoge el número de años máximo que un funcionario podía pasar en cada categoría: en el escalafón de 1895, se aprecia una promoción muy lenta; en cambio, a partir de principios del siglo XX, se aprecia una promoción mucho más rápida, aunque esta no estaba garantizada entre oficial de primera y jefe de negociado de tercera, porque requería aprobar un examen de ampliación. Este examen era muy completo e incluía pruebas de lectura y traducción de lengua inglesa o alemana, geografía postal universal, tratados postales vigentes y contabilidad general del Estado (Galvarriato, 1920: 1926).

En todo caso, el funcionamiento del mercado interno de trabajo se acercaba mucho a las aspiraciones de los funcionarios de considerar únicamente la antigüedad como criterio de ascenso dentro del cuerpo. En este sentido, esta transición a un sistema "automático» de promoción fue posible gracias a la expansión del cuerpo que no dependía de la aparición de vacantes por jubilación o defunción en la categoría inmediatamente superior. Así, mientras en 1895 los funcionarios podían pasar un período largo en cada una de las categorías, a partir de principios del siglo XX dicho período se redujo drásticamente. Solo en el caso de los oficiales de primera encontramos que algunos de ellos pasaban muchos años en la misma categoría sin promocionarse a jefes de negociado, quizá porque renunciaban al ascenso para no ser trasladados a otro destino o porque no superaban el examen de ampliación (aunque la evidencia de los escalafones parece demostrar que la gran mayoría de oficiales sí que superaban dicho examen). En la Tabla 5 detallamos los años máximos de permanencia en cada categoría profesional usando los escalafones de 1895, 1902, 1909 y 1921. En la misma tabla, también detallamos los años promedio de permanencia en la misma categoría para los 10 funcionarios más veteranos de esa misma categoría. En todos los casos, encontramos algún funcionario con muchos años de antigüedad en la misma categoría, pero también es evidente la aceleración entre 1895 y 1902, y luego entre 1909 y 1921 . La velocidad de las promociones internas mejora en el siglo XX, pero aún sigue dependiendo de los ciclos de expansión y congelación de la plantilla del cuerpo. También es evidente cómo entre las categorías directivas las promociones son mucho más rápidas que entre las de oficial. Destacan también los años 1919-1921, cuando se produjeron promociones bastante rápidas en las categorías superiores al aumentar en ellas el número de plazas. Por ejemplo, la categoría de jefe de administración de primera pasó de tener solo un ocupante a tener tres. Los jefes de administración de segunda clase pasaron de 4 a 12 y, los de tercera, de 15 a 32. Los jefes de negociado de primera pasaron de 22 a 64; los de segunda clase, de 31 a 107; y los de tercera clase, de 56 a 194. A raíz de este proceso, en 1921, la mayoría de jefes de administración y negociado habían sido ascendidos recientemente. 
TABLA 4

AÑOS MÁXIMOS EN CADA CATEGORÍA PROFESIONAL DE LOS FUNCIONARIOS ACTIVOS

\begin{tabular}{|c|c|c|c|c|c|c|c|c|}
\hline \multirow[b]{2}{*}{ Categoría } & \multicolumn{2}{|c|}{1895} & \multicolumn{2}{|c|}{1902} & \multicolumn{2}{|c|}{1909} & \multicolumn{2}{|c|}{1921} \\
\hline & Máximo & 10 primeros & Máximo & 10 primeros & Máximo & 10 primeros & Máximo & 10 primeros \\
\hline Jefe adm. $1 .^{\mathrm{a}}$ & 6 & & 13 & & 19 & & 1 & \\
\hline Jefe adm. $2 .^{a}$ & 6 & & 6 & & 1 & & 1 & \\
\hline Jefe adm. $3 .^{a}$ & 17 & & 1 & & 1 & & 1 & \\
\hline Jefe adm. $4 .^{\mathrm{a}}$ & 7 & & 1 & & 2 & & & \\
\hline Jefe negociado $1 .^{a}$ & 7 & 6,25 & 1 & 1 & 3 & 1,7 & 1 & 1 \\
\hline Jefe negociado $2 .^{a}$ & 12 & 7,5 & 2 & 1,1 & 3 & 2,2 & 1 & 1 \\
\hline Jefe negociado $3 .^{\mathrm{a}}$ & 9 & 7,5 & 2 & 1,3 & 4 & 3,5 & 1 & 1 \\
\hline Oficiales $1 .^{\mathrm{a}}$ & 16 & 9 & 16 & 10,4 & 19 & 9 & 16 & 9,6 \\
\hline Oficiales $2 .^{\mathrm{a}}$ & 11 & 9,4 & 3 & 2,4 & 5 & 4,1 & 0 & 0 \\
\hline Oficiales $3 .^{a}$ & 11 & 10,2 & 3 & 2,2 & 5 & 5 & 2 & 2 \\
\hline Oficiales $4 .^{a}$ & 11 & 10,3 & 2 & 2 & 5 & 5 & & \\
\hline Oficiales $5 .^{a}$ & 8 & 8 & 4 & 3,8 & 5 & 5 & & \\
\hline Aspirantes 1. ${ }^{\mathrm{a}}$ & 6 & 6 & 2 & 1,7 & & & & \\
\hline Aspirantes 2. & 1 & 1 & 0 & 0 & & & & \\
\hline
\end{tabular}

Fuente: Calculado a partir de los Escalafones del Cuerpo de Correos, 1895-1921. 


\begin{tabular}{|c|c|c|c|c|c|c|}
\hline & PROMOCI & NTERNA & $\begin{array}{l}\text { LA } 5 \\
\text { SS DIREC }\end{array}$ & S DEL CUE & & \\
\hline $\begin{array}{l}\text { INICIALES [Edad en } \\
\text { 1920] }\end{array}$ & $\begin{array}{c}\text { Cargo en } \\
1920\end{array}$ & $\begin{array}{c}\text { Cargo en } \\
1915\end{array}$ & $\begin{array}{c}\text { Cargo en } \\
1909\end{array}$ & $\begin{array}{l}\text { Cargo en } \\
1905\end{array}$ & $\begin{array}{l}\text { Cargo en } \\
1902\end{array}$ & $\begin{array}{l}\text { Cargo en } \\
1895\end{array}$ \\
\hline J. G. L. V. Q. [65] & Jefe adm. $1 .^{\mathrm{a}}$ & $\operatorname{Adm} .2 .^{\mathrm{a}}$ & $\operatorname{Adm} .3 .^{a}$ & $\begin{array}{c}\text { Negociado } \\
1 .^{\mathrm{a}}\end{array}$ & $\begin{array}{c}\text { Negociado } \\
1 .^{\text {a }}\end{array}$ & $\begin{array}{c}\text { Negociado } \\
3 .^{\mathrm{a}}\end{array}$ \\
\hline J. G. T. [59] & Jefe adm. 1. ${ }^{\mathrm{a}}$ & $\operatorname{Adm} .3{ }^{\mathrm{a}}$ & Neg. $1 .^{\mathrm{a}}$ & $\begin{array}{c}\text { Negociado } \\
2 .^{\mathrm{a}}\end{array}$ & $\begin{array}{c}\text { Negociado } \\
2 .^{\mathrm{a}}\end{array}$ & Oficial $1 .^{a}$ \\
\hline E. F. T. [62] & Jefe adm. $1 .^{\mathrm{a}}$ & Adm. 3. ${ }^{a}$ & Neg. 1. ${ }^{a}$ & $\begin{array}{c}\text { Negociado } \\
2 .^{\mathrm{a}}\end{array}$ & $\begin{array}{c}\text { Negociado } \\
3 .^{a}\end{array}$ & Oficial $1 .^{\mathrm{a}}$ \\
\hline M. M. P. [62] & Jefe adm. 2. ${ }^{a}$ & Adm. 3. ${ }^{a}$ & Neg. 2. ${ }^{\mathrm{a}}$ & $\begin{array}{c}\text { Negociado } \\
2 .^{\mathrm{a}}\end{array}$ & $\begin{array}{c}\text { Negociado } \\
3 .^{a}\end{array}$ & Oficial 2. ${ }^{a}$ \\
\hline I. A. T. [60] & Jefe adm. 2. ${ }^{\mathrm{a}}$ & $\operatorname{Adm} .3 .^{a}$ & Neg. 2. ${ }^{a}$ & $\begin{array}{c}\text { Negociado } \\
3 .^{\mathrm{a}}\end{array}$ & $\begin{array}{c}\text { Negociado } \\
3^{\mathrm{a}}\end{array}$ & Oficial 2. ${ }^{\mathrm{a}}$ \\
\hline J. S. T. F. [63] & Jefe adm. 2. ${ }^{\mathrm{a}}$ & $\operatorname{Adm} .3 .^{a}$ & Neg. 2. ${ }^{a}$ & $\begin{array}{c}\text { Negociado } \\
3 .^{\mathrm{a}}\end{array}$ & $\begin{array}{c}\text { Negociado } \\
3 .^{\mathrm{a}}\end{array}$ & Oficial 2. ${ }^{\mathrm{a}}$ \\
\hline J. M. J. L. M. [63] & Jefe adm. $2 .^{a}$ & Adm. 3. & Neg. 2. ${ }^{a}$ & $\begin{array}{c}\text { Negociado } \\
3 .^{\mathrm{a}}\end{array}$ & Oficial $1 .^{\mathrm{a}}$ & Oficial 2. ${ }^{\mathrm{a}}$ \\
\hline L. B. P. [60] & Jefe adm. $2 .^{\mathrm{a}}$ & Neg. $1 .^{\mathrm{a}}$ & Neg. 2. ${ }^{a}$ & Oficial $1 .^{\mathrm{a}}$ & & \\
\hline J. C. B. [65] & Jefe adm. $2 .^{\mathrm{a}}$ & Neg. 1. ${ }^{a}$ & Neg. 2. ${ }^{\mathrm{a}}$ & Oficial $1 .^{\mathrm{a}}$ & & \\
\hline J. M. P. [56] & Jefe $\operatorname{adm} .3 .^{\mathrm{a}}$ & Neg. $1 .^{a}$ & Neg. $3 .^{a}$ & Oficial $1 .^{\mathrm{a}}$ & & \\
\hline B. D. R. [64] & Jefe adm. $3 .^{a}$ & Neg. 1. ${ }^{a}$ & Neg. $3 .^{a}$ & Oficial $1 .^{\mathrm{a}}$ & & \\
\hline E. R. H. [56] & Jefe adm. $3 .^{a}$ & Neg. 1. ${ }^{a}$ & Neg. 3. ${ }^{a}$ & Oficial 1. ${ }^{\mathrm{a}}$ & & \\
\hline J. M. B. [52] & Jefe adm. $3 .^{\mathrm{a}}$ & Neg. 1. ${ }^{\mathrm{a}}$ & Neg. 3. ${ }^{\mathrm{a}}$ & Oficial $2 .^{\mathrm{a}}$ & & \\
\hline G. C. F. C. [52] & Jefe adm. $3{ }^{\mathrm{a}}$ & Neg. $1 .^{\mathrm{a}}$ & Oficial $1 .^{\mathrm{a}}$ & Oficial 2. ${ }^{\mathrm{a}}$ & & \\
\hline
\end{tabular}

Fuente: Escalafones del Cuerpo de Funcionarios de Correos.

Nota: Los funcionarios seleccionados son los de más alto nivel en 1920, según el escalafón de ese año. 
Un elemento fundamental en el análisis de las promociones es dilucidar cómo se reclutaban los jefes de administración (la categoría más alta del escalafón). En línea con la existencia de un rígido mecanismo de promoción dentro el mercado «interno» del cuerpo, los jefes de administración accedían a las categorías superiores después de aprobar el llamado «examen de ampliación» superando pruebas de lengua inglesa o alemana, contabilidad general del Estado y geografía postal global, y mediante traslados que permitían la promoción. Si miramos los escalafones más tardíos entre los que se han podido conservar, podemos recomponer la carrera completa de un directivo yendo desde 1895 , lo que nos daría una idea de las promociones realizadas por un nuevo entrante a finales del siglo XIX que llegara a un puesto directivo en los años 20.

El análisis de las carreras completas de varios funcionarios con posiciones directivas en 1921 muestra cómo se accedía al puesto de dirección máximo después de una larga experiencia de gestión en el cuerpo, con varios años de experiencia como "oficial» después de aprobar la oposición. Por ejemplo, en 1920, el funcionario de más rango del cuerpo tenía 65 años y 25 años de experiencia en cargos de dirección, con promociones más o menos regulares dentro del escalafón. En el caso de los siguientes funcionarios del escalafón, podemos ver cómo pasan 25 años entre su última experiencia como «oficiales» y su cargo actual. En general, se trata de experiencias laborales largas y continuadas de varias décadas en el mismo cuerpo hasta acceder a los puestos de dirección de mayor rango.

Esta promoción interna de los cargos directivos contrasta con la del director general del servicio de Correos, que era un cargo de designación política. Dada la inestabilidad política típica de la Restauración, estos cargos fueron muy volátiles. Por ejemplo, entre 1885 y 1920 hubo 37 directores generales. En algunos casos, como los de los directores generales que ocuparon su puesto entre diciembre de 1885 y julio de 1890 o entre febrero de 1910 y julio de 1913, la dirección fue algo estable. Sin embargo, años como 1892, 1900, 1917 y 1919 llegaron a tener tres directores generales sucesivos. De los 37 directores generales que hemos localizado en el período estudiado, 10 fueron personajes de la nobleza como el marqués de Mochales o el marqués de Lema.

\subsection{Traslados}

Una de las principales quejas de los funcionarios del Estado fueron los traslados, en muchos casos necesarios para ser promocionados. Esta fue, sin duda, una de las demandas importantes del movimiento juntista de funcionarios de 1917 (Villacorta Baños, 1989, p. 381) y un tema que aparece en varios debates parlamentarios. Especialmente, en las categorías de oficial, el 
sueldo no era suficiente como para hacer posibles traslados regulares, lo que forzaba a muchos funcionarios a renunciar al ascenso.

Hemos encontrado evidencia sobre los traslados que se decretaban cada mes a través de los avisos de movimiento de personal que se publicaban regularmente en la última página del Boletín Oficial de Correos. Según esta información, los traslados eran frecuentes. Según nuestros cálculos, usando el Boletín Oficial de Correos de 1909 y el escalafón del mismo año, alrededor de un $15 \%$ de los funcionarios cambiaban de destino en un año. Si los datos de 1909 son significativos, reflejan que un trabajador podía ser trasladado cada seis o siete años. En muchos casos, los ascensos estaban condicionados a los traslados y no parece que estos tuvieran en cuenta la proximidad geográfica con el destino previo. La Tabla 6 recoge algunos de los traslados que hemos encontrado, por ejemplo, en noviembre de 1909 (Boletín, noviembre 1909). Es difícil detectar un patrón en los traslados, aunque en algunos casos los traslados parecen estar asociados a emparejamientos entre funcionarios que desean permutar la plaza.

¿Existía algún determinante sistemático de los traslados? Por ejemplo, ¿eran más típicos de las categorías superiores o inferiores, o estaban asociados al ascenso y por tanto se concentraban, desproporcionadamente, en los funcionarios con más experiencia en cada categoría? Con este propósito, analizo la probabilidad de ser trasladado de 2.220 funcionarios que no están en licencia ilimitada del escalafón de 1909 usando un modelo probit en el que el trabajador que se traslada en 1909 toma valor 1 y el que no se traslada ese año, el valor 0 . Como variables explicativas utilizo el orden del funcionario en el escalafón de cada categoría ordenado por sus años de experiencia en esa categoría y el nivel de esa categoría. En el caso de que un ascenso reciente hubiera motivado el traslado, el rango en la categoría nueva debería explicarlo (el recientemente trasladado debería ser más novel en esa categoría). Podría usar edad o años de experiencia como variables

TABLA 6

EJEMPLOS DE TRASLADOS EN 1909

\begin{tabular}{|l|l|l|}
\hline Categoría & Destino inicial & Destino final \\
\hline Jefe negociado de 1. & Albacete & Inspección \\
Oficial 1. & Santander & Pontevedra \\
Oficial 5. ${ }^{\mathrm{a}}$ & Barcelona & Maqueda \\
Oficial 1.a & Mayorga (Valladolid) & Barcelona \\
Oficial 5. & Barcelona & Las Palmas \\
Oficial 5. & Oviedo & Santander \\
\hline
\end{tabular}

Fuente: Boletín Oficial de Correos. 
adicionales pero, en realidad, están muy correlacionadas con la categoría y los años de experiencia en esa categoría o con el orden de antigüedad en esa categoría.

Se presentan los resultados de la estimación en la Tabla 7. A pesar de nuestra hipótesis inicial de que los traslados estaban asociados a ascensos, la regresión muestra como el traslado no parece responder a ningún determinante sistemático. Los traslados parecen ser más comunes entre las categorías inferiores, aunque el coeficiente no llega a ser estadísticamente significativo al $10 \%$. En el caso del orden, los traslados no parecen obedecer, al menos en su totalidad, a ascensos recientes. En realidad, el modelo usado aquí explica una parte muy pequeña de la probabilidad de ser trasladado o de pedir el traslado, quizá porque en realidad no todos los traslados estaban asociados a ascensos sino a simples permutas de plazas. ${ }^{2}$ Si esto fuera así, los traslados no deberían verse como un elemento negativo de la gestión de recursos humanos en el cuerpo de funcionarios de Correos. Al acceder a la primera plaza, los oficiales seguramente tenían pocas opciones de escoger destino, lo que dependía en gran parte de las vacantes que hubiera. A medida que pasaba el tiempo, es probable que tuvieran la posibilidad de volver a sus lugares de origen o a destinos más acordes con sus preferencias.

\section{CONCLUSIONES}

Este artículo ha estudiado el mercado interno de trabajo en el Servicio de Correos a principios del siglo XX. En primer lugar, analizamos la evolución del empleo y los salarios reales. El empleo en Correos creció a partir de principios del siglo XX. Los salarios reales se mantuvieron relativamente estables hasta la primera guerra mundial, se vieron erosionados por la

TABLA 7

MODELO PROBIT DE LOS TRASLADOS

\begin{tabular}{|l|c|c|}
\hline & $\mathbf{d F} / \mathbf{d x}$ & Error estándar \\
\hline Categoría & 0,0093 & 0,0059 \\
Rango dentro categoría & 0,00004 & 0,00003 \\
$\mathrm{~N}$ & 2.220 & \\
$\chi^{2}$ & $8,17^{* *}$ & \\
Log-verosimilitud & -923 & \\
Media traslados & 0,147 & \\
Traslados que predice el modelo & 0,146 & \\
\hline
\end{tabular}

Nota: **significativo estadísticamente al $5 \%$. 
inflación asociada a esos años y experimentaron una gran mejora a partir de 1919. Cabe señalar aquí que gran parte de la mejora del salario real medio se debió a la evidente mejora de los salarios reales de los funcionarios encuadrados en las categorías inferiores del escalafón (desaparición de las categorías de oficial de quinta y de cuarta).

Analizando, específicamente, la carrera de los funcionarios, es evidente que esta ofrecía un futuro estable y sujeto a incrementos de sueldo regulares. En las cohortes estudiadas aquí, las probabilidades de separación del cuerpo son relativamente bajas y el funcionario experimentaba crecimientos regulares de su salario hasta conseguir que este mejorase de manera muy considerable. El coste inicial era una carrera laboral que empezaba relativamente tarde, dadas las características del mercado de trabajo de la España de principios de siglo, y puede que salarios algo bajos, dados los niveles de cualificación exigidos para entrar en el cuerpo. Sin embargo, a partir de las primeras categorías funcionariales, el funcionario experimentaba ascensos casi automáticos por años de experiencia que se traducían en importantes incrementos salariales. Además, la carrera funcionarial protegía particularmente el sueldo de los trabajadores mayores en línea con los modelos de mercados internos con «compensación diferida». Esto es, dada la desprotección de los trabajadores mayores en los mercados informales de principios del siglo XX, un excelente mecanismo de disciplina de la mano de obra era «prometer» un sueldo elevado en la vejez y una jubilación generosa (algo que solo podían prometer, de manera creíble, los servicios públicos o las grandes empresas, dada la inestabilidad de la pequeña y mediana empresa). Es en este sentido, los costes asociados a la pérdida del empleo son tan elevados que se soluciona el problema de motivación de la mano de obra en grandes empresas de servicios donde es imposible observar el rendimiento individual. En este contexto, los trabajadores, al estar su salario muy por encima de su productividad individual cuando son mayores, deciden permanecer con el empleador, aunque su productividad individual vaya disminuyendo, y se les tiene que «forzar» a jubilarse estableciendo una edad obligatoria de jubilación.

Sin embargo, el evidente atractivo de la carrera funcionarial en el contexto de los mercados de trabajo de la España de principios del siglo XX se veía afectado por varios factores. Por una parte, la probabilidad de ascender rápidamente en el escalafón dependía, crucialmente, de los períodos expansivos o contractivos del empleo agregado en Correos. En este sentido, el atractivo de la carrera funcionarial mejoró de manera ostensible en el siglo XX en comparación con finales del siglo XIX (a pesar de la funcionarización del cuerpo en 1889 y el fin de las cesantías asociadas al turno político). Muy singularmente, también la rigidez de las escalas salariales hacía que los

${ }^{2}$ En regresiones que no presentamos aquí, también hemos incluido una variable dummy para los casos de ascensos a nueva categoría, para ver si esto estaba correlacionado con los traslados. El coeficiente de esa variable es positivo, pero no es estadísticamente significativo. 
funcionarios fueran muy vulnerables a la evolución del coste de la vida. Por ejemplo, hemos dado cuenta de cómo la inflación asociada con la primera guerra mundial afectó a los salarios reales, lo que explica, en gran medida, la explosión juntista de varios cuerpos funcionariales del Estado.

En lo referente a la organización, Correos ofrecía, desde principios del siglo XX, una carrera laboral atractiva a sus funcionarios, con promociones automáticas y reclutamiento interno hasta los puestos directivos, lo que quizá permite argumentar que, aunque el sistema en general es probable que se pudiera mejorar mucho, desde comienzos del siglo XX el servicio sería eficiente en gran medida gracias a que compatibilizaba, aunque fuera de forma aún bastante rudimentaria, los intereses individuales de los funcionarios con las exigencias de un sistema de comunicaciones moderno.

\section{SUPPLEMENTARY MATERIALS}

To view Supplementary Materials for this article, please visit http://dx.doi. org/10.1017/S0212610915000154

\section{FUENTES}

Anuario Estadístico de España, varios años.

Anuario Postal, varios años.

Boletín Oficial de Correos.

Escalafones del Cuerpo de Funcionarios del Servicio de Correos.

\section{BIBLIOGRAFÍA}

Akerlof, G. (1982): «Labor Contracts as Partial Gift Exchange». Quarterly Journal of Economics 97 (4), pp. 543-569.

Ballesteros, E. y Martínez Vara, T. (2001): «La evolución del empleo en el sector ferroviario español, 1893-1935». Revista de Historia Económica-Journal of Iberian and Latin American Economic History 19 (3), pp. 637-678.

Ballesteros, E. y Martínez Vara, T. (2001b): «El mosaico de las profesiones ferroviarias. El caso de la compañía de Madrid a Zaragoza y a Alicante, 1857-1936», en C. Arenas; A. F. Puntas y J. Pons (eds.), Trabajo y relaciones laborales en la España contemporánea. Sevilla: Mergablum, pp. 53-64.

Воот, H. M. (1991): «Salaries and Career Earnings in the Bank of Scotland, 1730-1880». Economic History Review 44 (4), pp. 629-653.

Bоот, H. M. (1999): «Experience of Clerks at the East India Company». Economic History Review 52 (4), pp. 638-668.

Borderías, C. (1993): Entre líneas. Trabajo e identidad femenina en la España contemporánea: Telefónica, 1924-1980. Barcelona: Icaria.

Bordes Muñoz, J. C. (2001): «La depuración franquista de las funcionarias de Correos (1936-1975)». Historia y Comunicación Social 6, pp. 239-264. 
Brown, J. C. y Neumeier, G. (2001): «Job Tenure and Labour Market Dynamics during High Industrialization: the Case of Germany before World War I». European Review of Economic History 5 (2), pp. 189-218.

CAmps, E. (1985): «La teoría del capital humano: una contrastación empírica. La España industrial en el siglo XIX». Revista de Historia Económica VIII (1990), pp. 305-333.

CAMPS, E. (1995): La formación del mercado de trabajo industrial en la Catalunya del siglo $X I X$. Madrid: Ministerio de Trabajo.

Domenech, J. (2008): «Labour market adjustment a hundred years ago: the case of the Catalan textile industry, 1880-1913». Economic History Review 61 (1), pp. 1-28.

Escudero, A. (2001): «Mercado de trabajo, salarios y distribución de la renta en las minas de Vizcaya (1876-1936)», en C. Arenas; A. F. Puntas y J. Pons (eds.), Trabajo y relaciones laborales en la España contemporánea. Sevilla: Mergablum.

Fernández De Pinedo, E. (1992): "Beneficios, salarios y nivel de vida de los obreros de una gran empresa siderúrgica vasca, Altos Hornos de Vizcaya (1902-1927)». Revista de Historia Industrial 1, pp. 125-195.

Galvarriato, J. A. (1920): El Correo y la Telecomunicación en España. Disponible on-line en la biblioteca del foro histórico del Colegio Oficial de Ingenieros de Telecomunicación: $<$ http://www.coit.es/foro/?op=publicaciones_detalle\&idcategoria=286\&idlibro=237> (consultado el 8 de marzo de 2015).

Goldin, C. y Margo, R. (1992): "The Great Compression: the Wage Structure in the United States at Mid Century». Quarterly Journal of Economics CVII (1), pp. 1-34.

Howlett, P. (2004): "The Internal Labour Dynamics of the Great Eastern Railway Company, 1870-1913». Economic History Review LVII (2), pp. 396-422.

Huberman, M. (1995): Escape from the Market. Negotiating Work in Lancashire. Cambridge: Cambridge University Press.

Hunter, J. (2011): «Technology Transfer and the Gendering of Communications Work: Meiji Japan in Comparative Historical Perspective». Social Science Japan Journal 14 (1), pp. 1-20.

Jordana, J. y Ramió, C. (2005): «Gobierno y Administración», en A. Carreras y X. Tafunell, Estadísticas Históricas de España, siglos XIX-XX. Bilbao: Fundación BBVA, vol. III, pp. 973-1.026.

LazeAR, E. (1979): «Why Is There Mandatory Retirement?» Journal of Political Economy 87 (6), pp. 1.261-1.284.

Leunig, T. (2003): «A British Industrial Success: Productivity in the Lancashire and New England Cotton Spinning Industries a Century Ago» Economic History Review LVI (1), pp. 90-117.

Maluquer De Motes, J. (2005): "Consumo y precios», en A. Carreras y X. Tafunell, Estadísticas Históricas de España, siglos XIX-XX. Bilbao: Fundación BBVA, vol. III, pp. 1.247-1.296.

Martínez Lorente, G. (1993): "El mundo social del correo y el telégrafo», en A. Bahamonde Magro (ed.), Las comunicaciones en la construcción del Estado contemporáneo en España, 1700-1936. Madrid: Ministerio de Obras Públicas, Transportes y Medio Ambiente, pp. 233-254.

Martínez VARA, T. (2006): «Salarios y programas de bienestar industrial en la empresa ferroviaria MZA (1915-1935)». Investigaciones en Historia Económica 4, pp. 101-138.

Moreno, R. (2011): «El personal del Banco de España: desde su origen en el siglo XVIII hasta fin del siglo XIX». Banco de España-Estudios de Historia Económica, n. ${ }^{\circ} 59$.

NAím, M. (2015): The End of Power. Nueva York: Basic Books. 
Prados De La Escosura, L. (2005): El Progreso Económico de España. Madrid: Fundación BBVA.

RAFF, D. M. G. (1988): «Wage Determination Theory and the Five-Dollar Day at Ford». Journal of Economic History 48 (2), pp. 387-399.

RafF, D. M. G. y Summers, L. H. (1987): «Did Henry Ford Pay Efficiency Wages?» Journal of Labor Economics 5 (4), pp. S57-S86.

Reglamento orgánico del personal de Correos (1910): aprobado por Real Decreto de 11 de julio de 1909. Madrid.

SAStRe, M. (1905): Las huelgas de Barcelona y sus resultados en 1904. Barcelona: Tip. Industrial de Manuel Tarsi.

SAStRe, M. (1915): Las huelgas en Barcelona durante los años 1910 al 1914 ambos inclusive. Barcelona: Editorial Barcelonesa.

Saxonhouse, G. y Wright, G. (1984): «Two Forms of Cheap Labor in Textile History», en G. Saxonhouse y G. Wright (eds.), Technique, Spirit, and Form in the Making of Modern Economies. Essays in Honor of William N. Parker, Research in Economic History, Suplemento 3, pp. 3-31. Greenwich (US-CT): JAI Press.

Schapiro, C. y Stiglitz, J. (1984): «Equilibrium Unemployment as a Worker Discipline Device». American Economic Review 74 (3), pp. 433-444.

Seltzer, A. (2004): «Internal Labor Markets in the Australian Banking Industry: their Nature Prior to the Second World War and their Recent Decline». Accounting, Business \& Financial History 14 (3), pp. 237-256.

Seltzer, A. (2010): "Salaries and Promotion Opportunities in the English Banking Industry, 1890-1936». Business History 52 (5), pp. 737-759.

Seltzer, A. y Simons, K. (2001): "Salaries and Career Opportunities in the Banking Industry: Evidence from the Personnel Records of the Union Bank of Australia». Explorations in Economic History 38 (2), pp. 195-224.

Villacorta Baños, F. (1989): Profesionales y burócratas. Estado y poder corporativo en la España del Siglo XX, 1890-1923. Madrid: Siglo XXI. 